\title{
İşletmelerde Kaynak Temelli Bilgi Teknolojileri Yetkinliği: Bir Ölçek Uyarlama Çalışması
}

\author{
Information Technologies Competency of Enterprises: A scale adaptation Study
}

\author{
Ufuk TÜREN ${ }^{1}$, Yunus GÖKMEN², İsmail TOKMAK ${ }^{3}$
}

\begin{abstract}
ÖZET
Son yıllarda işletmelerde rekabet avantajı yaratan en önemli hususlardan birisi Bilgi Teknolojileri (BT) yetkinliği olarak görülmektedir. Mikro seviyede firma bazında BT yetkinliğini ölçmeye yönelik yazında bir takım çalışmalar bulunsa da ülkemizde konu üzerinde çalışacak araştırmacıların kullanabileceği, geçerliği ve güvenilirliği Türk firmaları üzerinde denemiş bir ölçeğin derlenerek gerekli testlerin yapılmasının yerli yazında önemli bir açığı kapatacağı ve BT yetkinliği ile diğer bazı değişkenler arasındaki ilişkileri incelemek için araştırmacılara fayda sağlayacağı düşünülmektedir. Bu çalışmada Tippins ve Sohi (2003) tarafından geliştirilen BT Bilgisi, BT Nesneleri ve BT Operasyonları olmak üzere üç boyuttan oluşan ölçek ele alınmıştır. Analizlerin sonucunda BT yetkinliği ölçeğinin Çorum'da bulunan bankalarda çalışan meslek memurları ve yöneticileri ile Ankara'daki imalat sanayi yöneticilerinden oluşan iki farklı örneklem için geçerli ve güvenilir olduğu belirlenmiştir.
\end{abstract}

Anahtar Kelimeler: Bilgi teknolojileri yetkinliği, ölçek uyarlama, geçerlik, çok değişkenli istatistik

\section{GiRiş}

Firma içinde bilgiyi etkin yönetmenin rekabet avantajı sağlamada gitgide artan önemi çoğu bilim adamı ve yönetici tarafından kabul edilmektedir. Geçmişte bir masraf kalemi olarak görülen bilgi yönetimi faaliyetleri günümüzde firmanın sahip olduğu önemli kaynaklardan birisi olarak görülmektedir (Barney, Wright ve Ketchen, 2001). Hatta bu kaynak koordinasyon, kontrol ve karar verme ile ilgili sağladığı destek ile firmanın diğer kaynaklarının etkin olarak kullanılabilmesi için en önde gelen husus olarak nitelendirilmektedir (Eser, 1991: 197-198, Stewart, 2000: 48). Bilgiyi etkin yönetebilmek için firmalar bilgi teknolojilerine yatırım yapmakta, yapılan yatırımın yanı sıra, sahip olunan teknolojik donanım ve yazılım ile bu sistemleri kullanmak için gereken bilgi birikimi ve uygulamalarla kazanılan operasyonel tecrübe birleşerek firmanın bilgi teknolojileri (BT) yetkinliğini oluşturmaktadır.

Sistem olarak ele alındığında, organizasyonun sınırları içinde ve dışında gelişen durumlar hakkında

\begin{abstract}
Information Technologies (IT) competency of enterprise is considered one of the important aspects for creating competitive advantage. Although some micro level scales measuring IT competency of firms are exist in the literature, in order to fulfill the requirement of a Turkish Scale measuring firm level IT capability by establishing its reliability and validity on Turkish enterprises can provide a significant contribution. This scale development study may be useful for scholar exploring the relationships of IT competency with other variables. In this study, IT competency which is developed by Tippins ve Sohi (2003) is held through three scales named; IT Knowledge, IT Objects and the success of IT operations. At the end of the analysis Turkish version of the IT competency scale is found to be reliable and valid considering two different samples. The first sample comprises the bank officials and managers in Çorum. And second one is consist of the managers of manufacturing industry firms in Ankara.
\end{abstract}

Keywords: Information technologies competency, scale adaptation, validity, multivariate statistics

karar vericilere veri ve bilgi akışı sağlayabilen BT'nin, sahip olan firmaya bu bilgilere erişme imkânı daha sınırı olan firmalara göre daha büyük rekabet üstünlüğü sağlayacağı söylenebilir (Barney, Wright ve Ketchen, 2001). Bu haliyle etkin ve verimli kullanılabilen BT kaynağının; firmaya mekân ve zaman mevhumu tanımadan çalışan duyargalar yoluyla veri ve bilgi sinyalleri aktardığı, bu veri ve bilgileri organize bir biçimde depolayabildiği, istenildiğinde erişime imkân verdiği ve analizler yoluyla doğru kararlar verme yeteneğini destekleyebildiği bilinmektedir (Bharadwaj, 2000).

BT, mikro elektronik aygıtlar ve programlanmış komutlar veya yazılımların yoğun bir biçimde kullanılmasını sağlayan bir çeşit sermaye donanımı olarak tanımlanabilmektedir. BT'nin tüm yazılım ve donanım sistemlerine uygulanabilir olmasa da bir takım belirgin özelliğinden söz etmek mümkündür. BT genel itibariyle; hızlı, hassas (isabetli), depolama kabiliyeti olan, kapasitesi yüksek, esnek, tekrar programlanabilir, otomatik ve otonom işlem yapabilme

\footnotetext{
1 Dr., Kara Harp Okulu, Endüstri ve Sistem Mühendisliği Bölümü, uturen2011@gmail.com

${ }^{2}$ Dr.,Kara Harp Okulu, Endüstri ve Sistem Mühendisliği Bölümü, yunusgokmen@gmail.com

${ }^{3}$ Dr., Milli Savunma Bakanlığı, ismail_tokmak@yahoo.com
} 
özelliğine sahip sistemlerdir. (Bensghir, 1996: 14) BT'nin; veri veya bilgiyi kaydetme, işleme, iletme, kullanıcılardan ve çevreden gelen bilgiler ve geri beslemelere az çok akıllı bir şekilde cevap verebilme yeteneğinin olması beklenmektedir. Günümüzde birçok sistem bu yeteneklerden sadece bir kısmına sahip olabilmekteyse de BT kullanımına tüm dünya üzerinde her türlü sektörde büyük ilgi gösterilmesinin altında yatan sebepler bu yeteneklerdir (Handel 2003).

Organizasyonların sahip oldukları BT, kurum içerisinde ve dışındaki aktörler arasında daha hızlı ve verimlibilgi iletme ve işleme imkânı sunmaktadır.Özellikle kurum içinde çeşitli kademelerde çalışanların faaliyetleri ile ilgili veri, bilgi ve tecrübelere ulaşmasında sağladığı kolaylık sayesinde görevler ile ilgili belirsizliklerin azaltılmasında etkin bir role sahip olabilmektedir (Huber, 1990; Bensaou, 1993). BT'nin organizasyonlara rekabet edebilme gücü kazandırmada olumlu etkilerinin olduğu bilinmektedir. Bu kazanım özellikle BT'nin organizasyona sağladığı hızıı bilgi işleyebilme ve dolayısıyla rakiplerden daha hızı karar verebilme, reaksiyon gösterebilme ve esneklik şeklinde gerçekleşmektedir (Porter ve Millar 1985). Ayrıca bilgi işleme faaliyetlerinin otomasyonu, zaman ve mekân kısıtlarının ortadan kaldıran teknolojiler ve iş zekâsı/ karar destek sistemleri uygulamaları yönetimin karar vermede ihtiyaç duyduğu bilgi ve tecrübî desteklerin maliyetini düşürmektedir (Malone, Yates ve Benjamin, 1987; Gurbaxani ve Whang, 1991). Her ne kadar İtalya'daki KOBi'ler üzerinde BT'in organizasyonel değişime etkilerini inceleyen çalışmalarında Giuri, Torrisi ve Zinovyeva (2008), BT'nin çalışanların yeteneklerinde bir gelişmeye neden olmadığını rapor etmiş olsalar da BT'nin organizasyonun çeşitli performans kriterleri üzerine etkilerinin olumlu yönde olduğunu gösteren çok sayıda çalışma mevcuttur (Michie ve Sheehan, 1999; Bharadwaj, 2000; Santhanam ve Hartono, 2003; Melville, Kraemer ve Gurbaxani, 2004; Bartel, Ichniowski ve Shaw, 2007; Zerenler, 2007; Majumdar, Carare ve Chang, 2010; Moshiri ve Simpson, 2011).

İşletme performansı üzerinde BT tetikleyici, kolaylaştırıcı ve gerçekleştirici üç temel rol oynamaktadır. BT'nin, işletmelerin performansını yükseltmede bir araç olmaktan öte, çağımızda organizasyonların değişmesi ve dönüşmesi sürecinde katalizör görevi oynadığı bilinmektedir (Chan, 2000).

BT ve onlar sayesinde ortaya çıkan organizasyon içi ve organizasyonlar arası bilgi ağlarının firmalara kattığı değerin ortaya konmasına yönelik çalışmalarda bilgi ağlarının kıymetinin sadece ekonomik değil, sosyal ve çevresel değişkenler bağlamında da ele alınması gerektiği de vurgulanmaktadır (Sharp, Irani ve Desai, 1999; Madureira, Baken ve Bouwman 2011). BT ile birlikte organizasyon içinde özellikle çalışanların yönlendirilmesi, performans ölçümü, işlerin daha etkin ve pratik dijital yardımcılar ile daha kolay ve ergonomik hale getirilmesi, veri toplamadaki kolaylık sayesinde iş etüdü yapma maliyetlerinin düşmesi ve süreçlerin daha görünür hale gelmesi ile süreç iyileştirme ve en iyileme imkânlarının ortaya çıkması da sağlanabilmektedir. Bartel, Ichniowski ve Shaw (2007) insan sermayesindeki gelişimin sebeplerinden biri olarak doğrudan BT'yi gösterirken, bazı çalışmalarda BT ile desteklenmiş teknolojik ve organizasyonel yenilikçilik yeteneklerinin örgütsel öğrenme, haberleşme, kurumsal bilgi yönetimi kavramları ile insan sermayesi üzerindeki olumlu etkisinden söz edilmektedir (Tanrıverdi, 2005; Evangelista ve Vezzani, 2011).

BT'nin aracılık etkisi ile ilgili bazı çalışmalar da bulunmaktadır. Zhou ve Chen (2009) organizasyonun BT yeteneklerinin hizmet sektörü örnekleminde sistem ömür devri içindeki çeşitli değişkenler arasında aracılık etkisinin bulunduğunu bildirmektedir. Loukis, Soto-Acosta ve Pazalos (2009) BT yatırımlarının aracılık etkisini elektronik iş stratejilerini benimseme ile performans arasındaki ilişkide aradıkları araştırmada BT yatırımlarının iş süreçlerinin yeniden tasarlanması başarısı ve örgüt performansı üzerinde doğrudan etkisini tespit etmiştir. Hsu ve Sabherwal (2011), Tayvan'daki büyük ölçekli firmalar örnekleminde gerçekleştirdikleri araştırmada, entelektüel sermaye ile yenilikçilik arasında bilgi yönetimi kabiliyetlerinin aracılık etkisi bulunduğu tespit etmişlerdir.

Yazında BT'nin organizasyonun başarı kriterleri üzerindeki etkisini ortaya koyabilmek maksadıyla birbirinden farklı yaklaşımlar ile birçok farklı ölçme yöntemi bulunmaktadır. BT'yi ölçmek konusunda mutabakat oluşmuş olmasa da yanlış yaklaşımlar ile yapılan ölçmelerin yanlı ve güvenilir olmayan sonuçlar doğurabileceği bilinen bir gerçektir. Buradan hareketle bir firmada BT'yi ölçmeye çalışmak yerine durumu kavramsal olarak daha iyi temsil eden BT yetkinliğini ölçmenin daha uygun olacağı düşünülmektedir.

\section{BT YETKINLIĞiNi DOĞRU ÖLÇMEK}

Yazında organizasyonel BT yetkinliğini ölçmek için çeşitli yöntemler kullanmıştır. Bunlardan birisi firmaların gerçekleştirdiği BT yatırımları toplamını bir gösterge olarak kabul eden yöntemdir. Burada göstergeye verilen isim BT değeridir ve para cinsinden ortaya konabilmektedir (Bknz. Sircar, Turnbow ve Bordoloi, 2000; Thatcher ve Oliver, 2001). Pratik gibi görünse de bu yöntem, genelde ucuzlayan 
donanım fiyatlarından kaynaklanan veri kirliliğini ve modası geçmiş veya atıl durumdaki donanım ve yazııımların maliyetlerini de içerdiğinden günümüzde pek tercih edilen bir yöntem değildir. (Martinsons ve Martinsons 2002). Çünkü BT değerine dâhil olan modası geçmiş sistem parçalarının üretime ve verimliliğe reel bir katkısı söz konusu değildir. Ayrıca geçmişte rekabet avantajı sağlayan unsurlar teknolojinin çok hızlı gelişmesi ve ucuzlaması ile kısa sürede sıradanlaşabilmektedir.

$\mathrm{Bu}$ ölçme problemini ortadan kaldırmak maksadıyla, günümüzde BT harcamaları yerine firmaların BT yeteneklerini ölçmeye çalışan kaynak tabanlı yöntemler rağbet görmektedir (Li, Chen ve Huang, 2006). Kaynak temelli değerlendirme yaklaşımı, bir varlığın rekabet avantajı sağlaması için iki şartın gerektiğini savunmaktadır. Bunlardan birincisi elde bulunan yeteneğin rakiplerin elinde bulunmaması, diğeri ise elde bulunan yeteneğin kolayca taklit edilememesidir (Barney, 1991). BT yetkinliği de bu iki şartı sağlayabildiği ölçüde firma için sürdürülebilir rekabet avantajı sağlayabilmektedir (Clemons ve Row, 1991). Çünkü önemli olan husus BT sistemlerine harcanan paradan çok bu sistemlerin ne kadar iyi olduğu, kurumsal olarak ne kadar etkin kullanıldığı ve ne kadar rekabet avantajı sağladığıdır. Taklit edilebilirliği, teknolojinin sürekli ucuzlaması ve erişilir olması özellikleriyle BT'nin kendisinin (yazılım, donanım, vb.) sürdürülebilir rekabet avantajı sağlaması mümkün görünmemektedir (Clemons ve Row, 1991). Dolayısıyla yıllık olarak BT'ye ayrılan bütçe, envanter, yaygınlık vb. kriterler ile BT'yi değerlendirmek ve bu ölçmeye dayalı sebep sonuç ilişkileri kurmak doğru sonuçlar vermeyebilir. Kaynak temelli değerlendirme yaklaşımı ise BT'nin sürdürülebilir stratejik avantajının ancak bütünlerlik (complementarity) ve birlikte uzmanlaşma (cospecialization) sayesinde korunabileceğini önermektedir (Powel ve Dent-Micallef, 1997). Burada "bütünlerlik" bir kaynağın değerinin diğer bir kaynağın varlığı ile büyümesi, diğer bir deyişle etkileşimle gerçekleşen sinerjik bir durumdur. Bu anlamda BT'nin değeri ona sahip olan firmanın müşteriler, pazar, rakipler, tedarikçiler vb. ile ilgili başarı için önemli bilgileri biriktirebildiği ve kullanabildiği bilgi depoları geliştirmesiyle büyüyebilir. Bilgiyi yönetebilme uzun vadeli rekabet avantajı için çok önemli bir meziyet olarak kabul edildiğinden BT'nin kıymetini büyütecektir. Burada örgütsel öğrenme, BT ile birlikte evirilerek bilgi üretimi sürecinde başarılı olabilmesi için önemli bir katalizör görevi yapabilir.

Birlikte uzmanlaşma ise bir kaynağın diğeri olmadan değersiz olabileceği tezini ileri sürmekte- dir (Clemons ve Row, 1991). Çok pahalı ve güncel donanımlara sahip bir firmanın bu sistemlerden verim alabilmesi ancak onları kullanabilecek bilgi birikimini, yetenek ve süreçlere sahip olması ile mümkün olabilmektedir. Tippins ve Sohi (2003) yazındaki çoğu çalışmanın aksine BT'yi organizasyonel bir yetenek olarak ele almış ve BT'nin gerçek değerinin ancak bu yolla ölçülürse doğru sonuçlara ulaşılabileceğini bildirmiştir. Bu yaklaşım sürdürebilir rekabet avantajı yaratması beklenen BT'nin değerlendirilmesi için zaman boyutuna duyarsız, dolayısıyla eskime ve modası geçme gibi riskleri ortadan kaldıran bir yaklaşım olabilmektedir. Tippins ve Sohi (2003) tarafından geliştirilen bu ölçeği Gibb ve Haar (2007) Yeni Zelanda; Ong ve Bin Ismail (2008), Said, Hui, Taylor ve Othman (2009) Malezya; Kmieciak, Michna ve Meczynska (2012), Polonya; öte yandan Fernández-Mesa, Ferreras-Méndez, Alegre-Vidal ve Chiva-Gómez (2012) İtalya ve İspanya örnekleminde uygulamıştır.

Türkiye'de şirketlerin BT yetenekleri veya imkânlarını ölçmeye çalışan bir takım çalışmalar olduğu tespit edilmiştir. Güleş, Gözlü ve Tekin (2003) BT uygulamalarının işletme performansı üzerinde olumlu etkileri olduğunu tespit ettikleri çalışmada işletmelerin elde bulundurduğu BT Uygulama Hedeflerine sahip olabilme becerisinin yapısal geçerliğini test etmiştir. BT Uygulama Hedeflerini oluşturan maddeler genel itibariyle işletmenin içi ve dış çevresiyle ne ölçüde veri/bilgi paylaşabildiği, depolayabildiği ve erişebildiği hususlarını sorgulamakta olup, topyekûn BT yetkinliğini ölçmede yeterli olamayabileceği görülmüştür.

Firmaların bilişim sistemlerinin işletme performansına etkisini ölçmek maksadıyla Akdede ve Turan (2008) kaynak temelli yaklaşımı kullanmışlardır. Powell ve Dent-Micallef (1997)'den uyarladıkları bu ölçek insan, işletme ve teknoloji kaynakları olmak üzere üç boyuttan oluşmaktadır. Söz konusu çalışmada bilişim sistemleri ölçeğinin Türkçe geçerliği ile ilgili istatistiksel bir test yer almamış sadece ölçeklerin Cronbach Alfa Değerleri rapor edilmiştir. Bu çalışmada insan kaynağı boyutunu ölçmeye yönelik ortaya konan ölçekte sadece genel insan kaynakları yönetimi kabiliyetlerini sorgulayan maddeler de bilişim yeteneğini sorgulayan maddelerle birlikte bulunmaktadır. Bu durum diğer boyutlar için de geçerlidir. Dolayısıyla bu karışık yaklaşımın işletmenin BT Yetkinliğini diğer yeteneklerinden ayrı ve bağımsız ölçme konusunda yeterli olamayacağı değerlendirilmiştir.

Turan (2009) ise BT'den elde edilen fayda ile işletmenin rekabet stratejisi yönelimleri arasındaki ilişkiyi irdelediği çalışmada şirketlerin mevcut BT 
imkânlarından ne kadar faydalanabildiğini ölçmeye yönelik bir ölçeği yine Powell ve Dent-Micallef'ten (1997) uyarlamıştır. Ölçeğin Türkçeye adaptasyonu bağlamında sadece Crombach Alfa Değerlerinin bildirildiği görülmektedir.

Bu çalışmanın maksadı, Tippins ve Sohi (2003) tarafından geliştirilip, kullanılan ve birçok farklı örneklemde farklı araştırmacılarca tercih edilmiş olan kaynak temelli yaklaşıma dayalı BT yetkinliği ölçeğinin Türkiye'de bulunan firmalar üzerinde geçerliliğini ve güvenirliğini araştırmak ve yazına Türkçe kaynak temelli bir BT yetkinliği ölçeği kazandırmaktır.

\section{KAYNAK TEMELLi BT YETKINLiĞi ÖLÇEĞi}

Küreselleşen dünyamızda örgütlerin sürdürülebilir rekabete iştirak edebilmeleri için bilgiye atfedilen önem gün geçtikçe artmaktadır. Dolayısıyla bilgiyi yönetebilme kabiliyetini arttıracak araç ve süreçlerin kazanılması, idamesi ve geliştirilmesi çok önemli bir husus olarak algılanmaktadır. Kaynak temelli bakışa göre, yeteneklerin büyük ölçüde taklit edilemez özeliklere sahip olması gerekir. Çünkü taklit edilebilir kaynak geliştirme ve yatırım faaliyetlerinin ticari anlamda yarattığı katma değer oldukça düşük olmaktadır. Taklit edilebilir olmamak ise gerçek rekabet avantajını oluşturmaktadır (Lei vd., 1996). Firmaların pazarda hâkimiyet sağlama mücadelesinde yüksek BT yetkinliğine sahip olmanın görünmeyen varlıkları yönetmede büyük üstünlük sağladığı düşünülmektedir (Itami, 1987). Tippins ve Sohi (2003) pazarlama, strateji ve bilgi bilim ve teknolojileri literatürüne dayandırdıkları kavramsallaştırmaları doğrultusunda BT yetkinliğini; firmaların BT hakkında ne kadar bilgili oldukları ve BT'yi firma içinde hangi etkinlik seviyesinde yönetebildikleri şeklinde tanımlamaktadır. Söz konusu kavramsallaştırma çabasının doğal bir varsayımı da firmaların BT nesnelerine (yazılım, donanım, BT personeli) sahip olmaları gerçeğidir. Birikimli olarak ele alındığında, BT yetkinliğinin birlikte uzmanlaşabilen kaynakları temsil eden üç boyuttan oluşabileceği ve birbiri ile etkileşimi olan ve birlikte gelişen bu boyutların pazar ve müşteri bilgilerini yönetmede ve BT nesne ve süreçlerini anlama ve onlardan faydalanma seviyesi için önemli bir gösterge olabileceği önerilmiştir. BT yeteneği ölçeği; BT nesneleri, BT bilgisi ve BT operasyonları boyutlarından oluşmaktadır. Birbirinden bağımsız olsalar da bu üç boyutun BT yetkinliğini oluşturmak için birlikte var olma ihtiyacı bulunmaktadır. Şöyle ki; firmalar çok büyük BT nesnelerine sahip olsalar da yeterli BT bilgisine sahip değillerse söz konusu nesneleri düzgün kullanamayacakları için BT yetkinliğine sahip olamayacaklardır (Tippins ve Sohi, 2003). Bu iki boyut ve bunların ticari hayattaki sonuçları şeklinde nitelendirilebilecek olan BT operasyonları devam eden bölümde ölçeğin üç alt boyutu olarak daha detaylı biçimde incelenmiştir.

\subsection{BT Nesneleri Boyutu}

Ölçeğin BT Nesneleri boyutu firmaların sahip oldukları BT ile ilgili fiziksel kaynaklar (donanım, ağ yapıları ve yazılım sistemleri) ile insan kaynağını (BT çalışanları) sorgulamayı hedeflemektedir (Gibb ve Haar, 2007). Söz konusu sorgulama mevcut teknolojik sistemlerin maliyetlerini dikkate almak yerine veri veya bilgiye erişme, işleme, depolama, dağıtma, paylaşma ve kullanma becerilerine sağladıkları katkı anlamında bir değerlendirmeyi esas almaktadır. Ayrıca ölçeğin bu boyutu BT sağlayıcı ve destekleyici kurumsal yapıların ve yetkin personelin varlığını da sorgulamaktadır (Tippins ve Sohi, 2003). Genel itibariyle BT Nesneleri, ölçeğin somut varlıklar boyutunu temsil etmek maksadıyla oluşturulmuştur.

\subsection{BT Bilgisi Boyutu}

Örgütsel öğrenme sürecinin bir sonucu olan örgütsel bilgi birikimi rekabette stratejik avantaj sağlamak için oldukça önemli bir örgütsel kaynak olarak tanımlanmaktadır (Schendel, 1996). Bilginin (knowledge) ve ham bilginin (information/malumat) deneyim, kapsam, yorumlama ve ifade edebilme kabiliyetleri ile birleşmesi ile vücut bulan bir kavram olduğu bilinmektedir. Bu haliyle bilgi önemli düzeyde örtük (tacit) bileşenlere sahiptir demek yanlış bir yaklaşım olmaz. Taylor (1971:43) teknik bilgiyi; arzulanan hedefe ulaşmak üzere sistemi değişime götüren prensip ve teknikler kümesi olarak tanımlamaktadır (aktaran, Tippins ve Sohi, 2003). Ayrıca, teknik bilgi bir şeyin veya işin nasıl yapılacağını bilebilme (knowhow) şeklinde de tanımlanmaktadır. Belirli şartlar altında, öngörülen maksatlara ulaşabilmek ancak doğru sıralanmış faaliyetler ve uygun karar mekanizma ve kuralları ile mümkün olabilmektedir. Diğer özel bilgi sahaları gibi BT Bilgisi de teknik bir alan olarak bilgi kavramının bir alt kümesi şeklinde ayırt edilebilecek özelliklere sahiptir (Tippins ve Sohi, 2003) . BT bilgisi örgüt dâhilindeki bilgi birikiminin bir alt kümesi olarak BT hususundaki bilişsel kazanım ve tecrübelerinin tamamın temsil etmekte ve soyutluğu hasebiyle ölçülmesi zor bir boyut olarak nitelendirilmektedir (Gibb ve Haar, 2007). Ölçeğin BT Bilgisi boyutu firmaların BT Nesneleri (Donanım, Ağ ve Yaziım Sistemleri) ve bunları kullanarak icra edilen ticari operasyonlar hakkında ne ölçüde bilgi ve beceri sahibi olduklarını ölçmeye yönelik kavramları içermektedir (Tippins ve Sohi, 2003). 


\subsection{BT Operasyonları Boyutu}

Firmalar iştigal ettikleri piyasalarda hedeflerine ulaşmak ve sürdürülebilir olabilmek maksadıyla teknik ve sosyal boyutu olan operasyon veya teknikler uygulamaktadır. Bu teknik operasyonlar belirlenmiş olan görevi başarmak için gereken yöntem, yetenek ve işlemleri içermektedir Bharadwaj (2000). Tippins ve Sohi'ye (2003) göre nihai ürün veya hizmeti ortaya koyabilmede izlenecek yolu ifade eden prosedürlerden oluşan teknik operasyonlar; Nelson, Peck ve Kalachek'in (1967) homojen olmayan işlemler ve Capon ve Glazer'in (1987) zihni basamaklar sırası şeklinde tanımladığı süreç teknolojisi fikri ile uyum halindedir (aktaran, Tippins ve Sohi, 2003). Dahası teknik operasyonlar teknik bilginin teknik operasyon ve kabiliyetlerin uygulanmasındaki tezahürü şeklinde de tanımlanmaktadır (Gibb ve Haar, 2007). Ölçeğin BT Operasyonları boyutu firmaların hangi ölçüde pazar ve müşteri veri ve bilgilerini yönetebildiğini kavramsallaştırmak ve ölçmek üzere oluşturulmuştur (Tippins ve Sohi, 2003).

\section{YÖNTEM}

\subsection{Bilgi Teknolojileri Yetkinliği Ölçeği}

Çalışmamızda ele aldığımız ölçek Tippins ve Sohi (2003) tarafından kaynak temelli bir yaklaşımla işletmelerin BT yeteneklerini ölçmek amaciyla oluşturulmuş ve $A B D$ 'de imalat sanayi yöneticileri üzerinde uygulanarak geçerli ve güvenilir olduğu bildirilmiştir (Şekil 1). Ölçek; "BT Operasyonları" 6 ifade, "BT Nesneleri" 5 ifade ve "BT Bilgisi" 4 ifade olmak üzere toplam üç boyuttan ve 15 ifadeden oluşmaktadır. Ölç̧ekteki sorular; "Müşteri bilgilerini çevrimiçi kaynaklardan toplayan bir takım imkânlarımız mevcuttur", "Şirketimizde resmi bir BT departmanı mevcuttur", "Firmamız her yıl yeni BT donanım ve yazılımlarının tedariki için önemli miktarda para ayırmaktadır", "Firmamız çalışanları bilgisayar ağı ile birbirlerine bağlanmıştır", "Firmamız yüksek seviyede bilgisayar temelli uzmanlığa sahiptir" şeklinde yargı cümlelerinden oluşmaktadır. Katılımcılar kendi işyerleri ile ilgili olarak bu ifadelere hangi oranda katıldıklarını 7'li likert tipi ölçek (1=Kesinlikle Katılmıyorum, 7=Kesinlikle Katılıyorum) üzerinde göstermişlerdir.

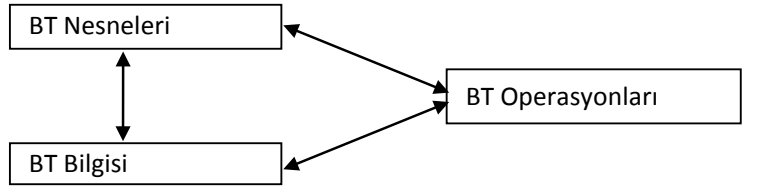

Şekil 1: BT Yetkinliği Ölçeğinin Boyutları (Tippins ve Sohi, 2003)

\section{2.Çeviri ve Dilsel Geçerlilik}

Çalışmada kullanılan BT Yetkinliği Ölçeği (Tippins ve Sohi, 2003)'nin İngilizce'den Türkçe'ye çevirisinde Brislin, Lonner ve Thorndike (1973) tarafından önerilen beş aşamalı model kullanılmıştır. Bahse konu model; orijinal dilden hedef dile ilk çeviri, yapılan ilk çevirinin değerlendirilmesi, orijinal dile yeniden çevrilmesi, orijinal dile yapılan çeviri ile özgün ölçeğin eşitliğinin değerlendirilmesi ve uzmanlarla son değerlendirme aşamalarından oluşmaktadır.

Çeviri aşamasında Savaşır (1994)'ın belirttiği gibi çevirmenler; hedef ve kaynak dili iyi bilme, ölçeğin ilgili olduğu konuyu bilme ve her iki kültürde deneyim sahibi olma gibi ölçütler dikkate alınarak belirlenmiştir. Bu bağlamda ölçek maddelerinin orjinal dilden hedef dile çevrilmesi işlemi birbirinden bağımsız bir şekilde üç kişi tarafından yapılmıştır. Çevirmenlerin ana dili Türkçedir. Çevirmenlerden birincisi İngilizce öğretim elemanı, diğerleri ise her iki dile de hâkim olan çalışmanın yazarlarından ikisidir. Birinci çevirmenin de kendi alanı dışında BT konularında akademik çalışmaları mevcut olup alanla ilgili bilgisi bulunmaktadır.

Yapılan ilk çevirinin sonrasında ortaya çıkan taslaklar; ikisi bu alanda akademik çalışmaları olan, diğeri ise Türk Dili ve Edebiyatı öğretim elemanı olmak üzere üç kişilik akademisyen grubu tarafından değerlendirilmiştir. Değerlendirmede her üç çeviri ayrı ayrı ele alınarak; her bir maddenin ve kelimenin Türkçe dilbilgisi kurallarına ve alanda kullanılan literatüre uygun olup olmadığı ile genel olarak metinlerin anlaşııır olup olmadığı incelenmiştir. Elde edilen son taslak farklı bir İngilizce öğretim elemanı tarafından yeniden İngilizceye çevrilmiş, yazarların ve İngilizce öğretim elemanlarının oluşturduğu değerlendirme grubu orijinal ölçekle yeniden İngilizceye çevrilerek elde edilen taslağı karşılaş̧ırmış ve karşılaştırma sonucunda birbirleri ile uyuştuğu sonucuna varılmıştır.

Çevirisi yapılan ve elde edilen ölçekle ilgili son olarak birisi BT konusunda faaliyet gösteren bir işletmede mühendis olarak çalışan, diğeri bir kamu kurumunun BT işlemlerinden sorumlu departman yöneticisi olarak görev yapan konunun profesyoneli iki uzmanında görüşü alınmış ve ölçekte geçen ifadelerin çalışma hayatında bu alanda kullanılan ifadelerle örtüşüp örtüşmediğinin değerlendirilmesi istenmiş ve bu konu ile ilgili her iki uzmanın da olumlu görüş belirtmesi sonucu ölçeğin elde edilen Türkçe çevirisinin araştırmada kullanılabileceğine karar verilmiştir. 


\section{3.İstatistiksel Analiz}

Çalışma kapsamında her iki örneklemden elde edilen verilerin analiz edilmesinde SPSS 16.0 ile Amos 21.0 paket programları kullanılmıştır. Ölçeğin iç tutarlılığı için Cronbach Alpha katsayılarına bakılmış, yapısal geçerliliği için ise önce açımlayıcı müteakiben doğrulayıcı faktör analizleri uygulanmıştır.

\section{4.Örneklem}

\subsubsection{Birinci Örneklem}

BT Yetkinliği Ölçeğinin Türkçeye uyarlanması çalışmasında iki ayrı örneklem grubu kullanılmıştır. Birinci örneklem hizmet sektöründe BT yetkinliğinin önemli olduğunu değerlendirdiğimiz bankacılık sektöründen alınmış olup Çorum il merkezinde faaliyet gösteren kamu ve özel bankalarda çalışan meslek memurları ve yöneticilerden oluşmaktadır. Çorum il merkezinde (çalışmanın yapıldığı sırada) 3'ü kamu, 14'ü özel olmak üzere toplam 17 ayrı banka faaliyet göstermektedir. Kamu bankalarının 9, özel bankaların 23 olmak üzere toplam 32 banka şubesi mevcuttur. Bu şubelerde meslek memuru ve yönetici olarak 400 civarında personel görev yapmaktadır. Çalışma kapsamında; tanımlayıcı istatistiklere ilişkin sorular ile BT yetkinliği ölçeğinden oluşan anket formu çoğaltılarak her banka şubesine meslek memurları ve yöneticiler tarafından doldurulmak üzere teslim edilmiş ve 15 gün sonra toplanmıştır. Çalışma kapsamında 129 anket cevaplanmış, yapılan incelemede uygun cevaplanmayan (eksik işaretleme, aynı ifadede birden fazla şık işaretleme vb.) 21 anket çalışma dışı bırakılarak 108 anket çalışma kapsamına alınmıştır. Katılımcıların \%42,5'i (N=46) kamu bankalarında, \%57,5'i ( $\mathrm{N}=62$ ) özel bankalarda çalışmaktadır (Örnekleme ilişkin detaylı bilgiler Tablo.1'de sunulmuş̧ur.

Tablo 1: Birinci Örnekleme İlişkin Tanımlayıcı İstatistikler

\begin{tabular}{|c|c|c|c|c|c|c|c|}
\hline \multicolumn{8}{|c|}{ Katılımcıların Özellikleri } \\
\hline \multirow{2}{*}{ Yaş } & Ort. & S.S. & 20-30 yıl & $31-40$ yıl & 41-50 yıl & \multicolumn{2}{|c|}{$51-60$ yıl } \\
\hline & 33 & 6,57 & $47(\% 43,5)$ & $42(\% 38,9)$, & $17(\% 15,7)$ & \multicolumn{2}{|c|}{$2(\% 1,9)$} \\
\hline \multirow{2}{*}{ Cinsiyet } & \multicolumn{4}{|c|}{ Erkek } & \multicolumn{3}{|c|}{ Kadın } \\
\hline & \multicolumn{4}{|c|}{$37(\% 34,3)$} & \multicolumn{3}{|c|}{$71(\% 65,7)$} \\
\hline \multirow{2}{*}{ Pozisyon } & \multicolumn{4}{|c|}{ Yönetici } & \multicolumn{3}{|c|}{ Meslek Memuru } \\
\hline & \multicolumn{4}{|c|}{$23(\% 21,3)$} & \multicolumn{3}{|c|}{$85(78,7)$} \\
\hline \multirow{2}{*}{ Eğitim } & \multicolumn{3}{|c|}{ Önlisans } & \multicolumn{2}{|c|}{ Lisans } & \multicolumn{2}{|c|}{ Lisansüstü } \\
\hline & \multicolumn{3}{|c|}{$6(\% 5,6)$} & \multicolumn{2}{|c|}{$87(\% 80,6)$} & \multicolumn{2}{|c|}{$15(\% 13,9)$} \\
\hline \multirow{2}{*}{$\begin{array}{c}\text { Mevcut } \\
\text { İşyerindeki } \\
\text { Çalışma Süresi }\end{array}$} & Ort. & S.s. & $1-5$ yıl & 6-10 yıl & $11-15$ yıl & $16-20$ yıl & 21 yıl ve üstü \\
\hline & 6,58 & 4,91 & $57(\% 52,8)$ & $29(\% 26,8)$ & $19(\% 17,6)$ & $1(\% 0,9)$ & $2(\% 1,9)$ \\
\hline
\end{tabular}

\subsection{2.İkinci Örneklem}

Araştırmanın ikinci örneklemini Ankara ili OSTiM Sanayi Sitesinde; Teknoloji ve Bilişim, Elektrik ve Elektronik ile Makine ve Makine Ekipmanları alt sektörlerinde faaliyet gösteren işletmeler oluşturmaktadır. Bu sektörlerin belirlenmesinde, BT yetkinliğinin görece olarak diğer sektörlere göre daha önemli olması esas olmuştur. Verilerin toplanmasında, hazırlanan web tabanlı anket formu 1054 işletmeye e-posta ile gönderilerek, anketlerin, bulundukları pozisyon itibariyle işletmenin BT yetkinliğini daha iyi değerlendirilebilecekleri düşünüldüğünden orta veya üst düzey yöneticiler tarafından doldurulması istenmiştir. İki aylık süre zarfında 221 işletme yöneticisi anket formunu doldurmuştur. Yapılan kontroller sonucunda anketlerden ancak 203'ünün tam olarak doldurulduğu tespit edilmiş ve analizlere katılması uygun görülmüştür. İşletmelerin \% 67,9'u ( $N=138)$ KOBI, \%32,'i (N=65) büyük işletme statüsündedir. Örnekleme ait detaylı bilgiler Tablo 2'de sunulmuştur. 
Tablo 2: İkinci Örnekleme İlişkin Tanımlayıcı İstatistikler

\begin{tabular}{|c|c|c|c|c|c|c|c|c|c|c|}
\hline \multicolumn{11}{|c|}{ Araştırma Kapsamındaki İşletmelere İlişkin Özellikler } \\
\hline \multirow{2}{*}{ İşletme Yaşı } & Ort. & S.S. & \multicolumn{2}{|c|}{$1-10 \mathrm{yıl}$} & \multicolumn{2}{|c|}{$11-20 \mathrm{yll}$} & \multicolumn{2}{|c|}{$21-30 \mathrm{yıl}$} & $31-40 \mathrm{yıl}$ & 41 yıl ve üstü \\
\hline & 22,10 & 14,19 & \multicolumn{2}{|c|}{$46(\% 22,6)$} & \multicolumn{2}{|c|}{$60(\% 29,5)$} & \multicolumn{2}{|c|}{$49(\% 24,1)$} & $21(\% 10,3)$ & $27(\% 13,5)$ \\
\hline \multirow{3}{*}{$\begin{array}{c}\text { Personel } \\
\text { Sayısı/ İşletme } \\
\text { Büyüklüğü* }\end{array}$} & \multicolumn{8}{|c|}{ KOBi } & \multirow{2}{*}{\multicolumn{2}{|c|}{$\begin{array}{l}250 \text { kişi ve üstü } \\
\text { Büyük İşletme }\end{array}$}} \\
\hline & \multicolumn{2}{|c|}{$\begin{array}{c}\text { 1-9 kişi } \\
\text { Mikro İşletme }\end{array}$} & \multicolumn{4}{|c|}{$\begin{array}{c}\text { 10-49 kişi } \\
\text { Küçük İşletme }\end{array}$} & \multicolumn{2}{|c|}{$\begin{array}{c}\text { 50-249 kişi } \\
\text { Orta Boy Iş̧letme }\end{array}$} & & \\
\hline & \multicolumn{2}{|c|}{$10(\% 4,9)$} & \multicolumn{3}{|c|}{$39(\% 19,2)$} & & \multicolumn{2}{|c|}{$89(\% 43,8)$} & \multicolumn{2}{|c|}{$65(\% 32,1)$} \\
\hline \multirow{2}{*}{ Sermaye Yapısı } & \multicolumn{3}{|c|}{ Yerli Sermaye (\%100 Yerli) } & \multicolumn{5}{|c|}{ Yerli-Yabancı Ortaklığı } & \multicolumn{2}{|c|}{$\begin{array}{c}\text { Yabancı Sermaye (\%100 } \\
\text { Yabancı) }\end{array}$} \\
\hline & \multicolumn{3}{|c|}{$141(\% 69,5)$} & & \multicolumn{4}{|c|}{$35(\% 17,2)$} & \multicolumn{2}{|c|}{$27(13,3)$} \\
\hline \multicolumn{11}{|c|}{ Katılımcıların Özellikleri } \\
\hline \multirow{2}{*}{ Yaş } & Ort. & s.s. & \multicolumn{3}{|c|}{$20-30$ yıl } & \multicolumn{3}{|c|}{$31-40 \mathrm{yıl}$} & $41-50$ yıl & $51-60$ yıl \\
\hline & 35,08 & 7,34 & \multicolumn{3}{|c|}{$66(\% 32,6)$} & \multicolumn{3}{|c|}{$90(\% 44,3)$} & $39(\% 19,2$ & $8(\% 3,9)$ \\
\hline \multirow{2}{*}{ Cinsiyet } & \multicolumn{6}{|c|}{ Erkek } & \multicolumn{4}{|c|}{ Kadın } \\
\hline & & & (\%77, & & & & & & $5(\% 22,2)$ & \\
\hline & & ve altı & & & sans & & & Lisans & & süstü \\
\hline сgाтाпा & & $63,4)$ & & 17 & (08,4) & & & $9(\% 58,6)$ & & $629,6)$ \\
\hline İşyerindeki Çalışma & Ort. & S.S. & & $1-5 \mathrm{yll}$ & & $6-10$ & & $11-15 \mathrm{yll}$ & $16-20 \mathrm{yıl}$ & 21 yıl ve üstü \\
\hline Süresi & 6,77 & 5,97 & 112 & $2(\% 55,2)$ & & $45 \%$ & & $28(\% 13,8)$ & $12(\% 6)$ & $6(\% 2,9)$ \\
\hline
\end{tabular}

(Not: * KOBI / büyük işletme ayrımı yapılırken Küçük ve Orta Büyüklükteki İşletmelerin Tanımı, Nitelikleri ve Sınıflandırılması Hakkında Yönetmelikte ifade edilen personel sayıları esas alınmıştır.)

\section{BULGULAR}

\section{1.ìç Tutarlılık Analizi}

Ölçeklerin güvenilirliğinin (içsel tutarlılığının) değerlendirilmesinde en yaygın kullanılan metotlardan biri de Cronbach alfa testidir ve bu katsayının 0.70 'den büyük olup olmadığının kontrol edilmesi gerekir.(Bülbül ve Demirer, 2008). Ölçeğin iç tutarlılığını ölçmek maksadıyla her iki örneklemin alt boyutların iç tutarlılıkları hesaplanmış ve Tablo 3'te gösterilmiştir Alt boyutlara ait Cronbach Alfa katsayıları birinci örneklem için 0,906 ile 0,944 arasında değişkenlik gösterirken; ikinci örneklem için 0,912 ile 0,947 arasında gerçekleşmiştir. Öte yandan ölçeğe ait toplam Cronbach Alfa katsayısı, birinci örneklem için 0,966 ikinci örneklem için 0.968 şeklinde elde edilmiştir ve her iki Cronbach Alfa değerleri 0,70'den büyüktür. Ayrıca her iki örnekleme ait ölçekte yer alan maddelerin düzeltilmiş madde toplam korelasyonlarının tamamının 0,70 'den büyük olduğu ve bu yüzden varsayılan 0,20 değerinden (Büyüköztürk, 2007) yüksek olduğu tespit edilmiştir. Sonuç olarak bu bulgular ışığında ölçeğin iç tutarlığının sağlandığı söylenebilir.
Tablo 3: İç Tutarlılık Analizi

\begin{tabular}{|l|c|c|}
\hline \multirow{2}{*}{$\begin{array}{l}\text { Alt Boyutlar } \\
\text { (Faktörler) }\end{array}$} & 1.Örneklem & 2.Örneklem \\
\hline BiT Operasyonları & 0,944 & $(\alpha)$ \\
\hline BiT Nesneleri & 0,916 & 0,947 \\
\hline BiT Bilgisi & 0,906 & 0,918 \\
\hline TOPLAM & 0,966 & 0,912 \\
\hline
\end{tabular}

(Not: $\mathrm{a}=$ Cronbach Alfa)

\subsection{Açımlayıcı Faktör Analizi (AFA)}

BT yetkinliği ölçeğini oluşturan 15 madde Ek-A'da sunulmuştur. Toplanan iki örneklemin verilerinin yapısal geçerliliği araştırmak maksadıyla Açımlayıcı Faktör Analizine (AFA) tabi tutulmuştur. Her iki örnekleme analiz öncesinde uygulanan KMO ve Barlett Testleri eldeki veri kümesinin faktör analizine uygun olduğunu göstermiştir. Her iki örneklemde analize giren maddeler üç faktör altında oldukça yüksek faktör yükleri ile toplanmıştır. Her iki örneklemde üç faktörün toplam varyansı açıklama oranı yaklaşık \%79 seviyesinde ve ölçeğin yapısal geçerliğini destekler durumdadır. Ayrıca yorumlanabilir, anlamlı faktörler elde etmek maksadıyla her iki örnekleme ait Bileşen Matrisi, literatürde yaygın olarak kullanılan Varimax yöntemi ile döndürülmüş ve Tablo 4'teki bulgular elde edilmiştir. 
Tablo 4: BiT Yetkinliği Ölçeğinin Açımlayıcı Faktör Analizi Sonuçları (1 ve 2.Örneklem)



Tablo 4 incelendiğinde, her iki örnekleme ait faktör yükleri 0,50 'den büyük olduğu ve iki faktöre giren faktör yüklerinin arasındaki farkın da 0,1'den büyük olduğu görülmektedir (Tavşancıl, 2002). Ayrıca tüm faktör yükleri, Meyers, Gamst ve Guarino'nun (2005: 507) belirttiği gibi, 0,6'nın üzerinde olduğundan "iyi" seviyede bulunmuştur.

\subsection{Doğrulayıcı Faktör Analizi (DFA)}

Açımlayı́ı Faktör Analizinden elde edilen bulgular ışında önerilen ölçeğin her iki örneklem için geçerliğinin ve güvenilirliğinin test etmek iç̧in Doğrulayıcı Faktör Analizi (DFA) uygulanmıştır. Her iki örnekleme ait Doğrulayıcı Faktör Analizi (DFA) sonuçları karşılaştırmalı olarak Tablo 5 'te ve örneklemlere ait DFA faktör yapısı Şekil 2 ve 3'te detaylı olarak gösterilmiştir. 
Tablo 5: Doğrulayıcı Faktör Analizi (DFA) Sonuçları

\begin{tabular}{|c|c|c|c|c|c|}
\hline \multicolumn{2}{|r|}{ Parametreler } & Kısaltması & $\begin{array}{l}\text { Mükemmel } \\
\text { Uyum Eşik }\end{array}$ & 1. Örneklem & 2.Örneklem \\
\hline \multirow{7}{*}{$\begin{array}{l}\text { Uyum } \\
\text { Indeksleri }\end{array}$} & $\begin{array}{l}\text { Uyum İyiliği İndeksi } \\
\text { (Goodness of Fit Index) }\end{array}$ & GFI & $\geq 0,90^{\ominus}$ & 0,875 & 0,937 \\
\hline & $\begin{array}{l}\text { Düzeltilmiş Uyum İndeksi } \\
\text { (Adjusted Goodness of Fit Index) }\end{array}$ & AGFI & $\geq 0,90^{\star}$ & 0,776 & 0,888 \\
\hline & $\begin{array}{l}\text { Karşılaştırmalı Uyum İndeksi } \\
\text { (Comparative Goodness of Fit Index) }\end{array}$ & CFI & $\begin{array}{l}\geq 0,85^{\Omega} \\
\geq 0,90^{\circ} \\
\geq 0,93^{\ominus}\end{array}$ & 0,969 & 0,989 \\
\hline & $\begin{array}{l}\text { Normalleştirilmemiş Uyum İndeksi } \\
\text { (Non-normal Fit Index) }\end{array}$ & NNFI & $\geq 0,90^{*}$ & 0,951 & 0,983 \\
\hline & $\begin{array}{l}\text { Normalleştirilmiş Uyum İndeksi } \\
\text { (Normal Fit Index) }\end{array}$ & NFI & $\begin{array}{l}\geq 0,90^{\ominus} \\
\geq 0,95^{\sqcap}\end{array}$ & 0,931 & 0,969 \\
\hline & $\begin{array}{l}\text { Yaklaşık Hataların Ortalama Karekökü } \\
\text { (Root-Square-Mean Error of Approximation) }\end{array}$ & RMSEA & $\begin{array}{l}\leq 0,05^{\prime} \\
\leq 0,08^{*}\end{array}$ & 0,086 & 0,049 \\
\hline & $\begin{array}{l}\text { Minimum Tutarsızlık } \\
\text { (Minimum Discrepancy) }\end{array}$ & CMIN/DF & $\begin{array}{l}\leq 2^{*} \\
\leq 5^{n}\end{array}$ & 1,746 & 1,506 \\
\hline \multirow{4}{*}{$\chi^{2}$ Testi } & Örneklem Boyutu & $\mathrm{N}$ & & 108 & 203 \\
\hline & Serbestlik Derecesi & SD & & 67 & 67 \\
\hline & $\chi^{2}$ Değeri & $\chi^{2}$ & & 116,973 & 100,934 \\
\hline & Anlamlııı̆ın Kesin Düzeyi & $\mathrm{P}$ & $\leq 0,05$ & 0,000 & 0,014 \\
\hline
\end{tabular}

( Not: $\left(^{(2)}\right.$ : Bollen (1989). ( $\left.{ }^{\ominus}\right)$ : Byrne (1994) (П): Schumacker ve Lomax (2004).(^): Hu ve Bentler (1999)

$\left({ }^{*}\right)$ : Steiger (1990) (*): Browne ve Cudeck (1993) (*): Marsh ve Hocevar (1985); Ullman, (2001))

Tablo 5 incelendiğinde; her iki örneklemin analizlerine ait $\chi^{2}$ sınamasına göre $p=0,014<\alpha=0.05$ olduğundan, modelin \%95 güvenirlilik düzeyinde anlamlı olduğuna karar verilebilir. Ayrıca Tablo 5'teki ikinci örnekleme ait değerler incelendiğinde; uyum indekslerinin biri $(A G F I=0,888)$ hariç tamamının belirtilen mükemmel uyum eşik değerleri sağladığı (GFl=0,937 $\mathrm{CFl}=0,989 \mathrm{NNFl}=0,983 \mathrm{NFl}=0,969 \mathrm{RM}-$ $\mathrm{SEA}=0,049 \mathrm{CMIN} / \mathrm{DF}=1,506$ ) ve bu değerlerin birinci örnekleme ait değerlerden daha iyi olduğu görülmektedir. Bu veriler ışığında model ve gözlenen veriler arasında uyum bulunduğu ve önerilen modelin iyi düzeyde uyum gösterdiği söylenebilir. AGFI değeri incelendiğinde her ne kadar mükemmel uyum eşik değerini $(>0,90)$ geçmese de kabul edilebilir sınırlar içinde $(0.85 \leq 0,888 \leq 0.90)$ olduğu görülmektedir
(Schermelleh, Moosbrugger ve Müler, 2003). Literatürde GFI, AGFI, NFI, NNFI ve CFI değerlerinin 0.90 civarında ve üzerinde RMSEA ve RMR değerlerinin ise 0.10 'dan düşük çıkması modelin gerçek verilerle uyumu için birer ölçüt olarak kabul edilmektedir (Anderson ve Gerbing 1984, Becker, Hagenberg, Roessner, Woerner ve Rothenberger, 2004). Örneklem miktarı artırıldıkça bu AGFI değeri rahatlıkla eşik değerini geçebileceği söylenebilir. Ayrıca $\chi^{2} / S D$ oranının $(100,934 / 67=1,506) 0-5$ arasında olması beklenir (Anderson ve Gerbing, 1984; Tabachnick ve Fidel, 2007: 721; Schermelleh, Moosbrugger ve Müler, 2003). Uyum indekslerinden elde edilen değerler DFA ile ortaya çıkan üç bileşenli yapının kabul edilebilir bir model olduğu, dolayısıyla söz konusu ölçeğin Türk kültürü için de özgün yapısını koruduğu söylenebilir. 


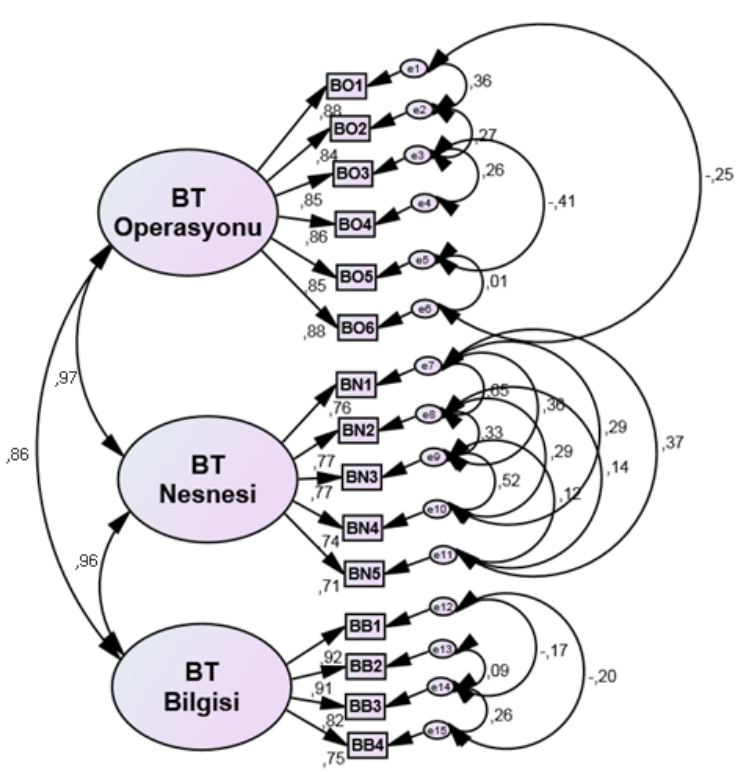

Şekil 2: Birinci Örneklemin DFA Faktör Yapısı

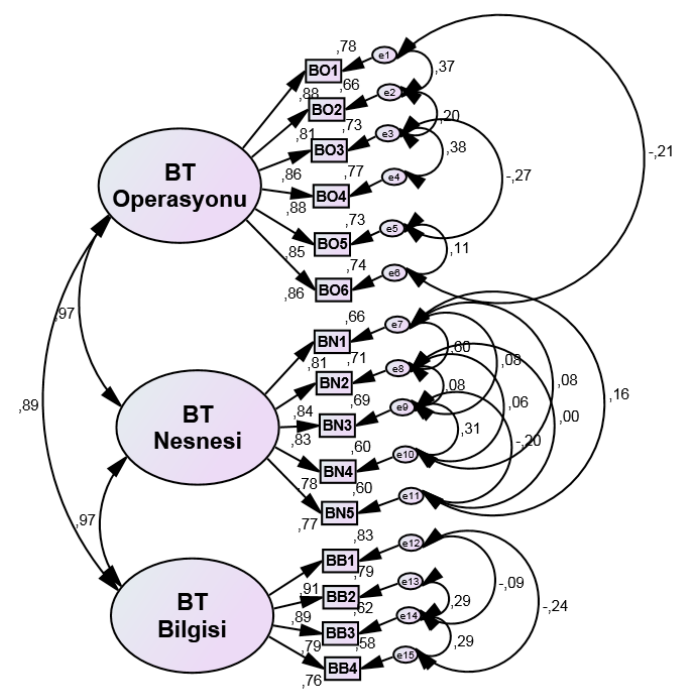

Şekil 3: İkinci Örneklemin DFA Faktör Yapısı

\section{SONUÇ VE TARTIŞMA}

Son yıllarda işletmelerin en önemli rekabet güçlerinden biri olarak kabul edilen bilgi ve iletişim teknolojileri kabiliyetinin ölçülebilir hale gelmesi örgütlerin kendi durumlarını ölçebilmeleri ve anlayabilmeleri açısından oldukça önemli bir husustur. Yazında rastlanan bir takım ölçeklerin güncelliklerini çok kısa sürede kaybedecek biçimde tasarlanmış olduğu da görülmektedir. Bu anlayışla tasarlanan ve opera- syonel hale getirilen ölçeklerin çok yanıltıcı sonuçlar verebileceği de yukarıda tartışılmıştır.

Kaynak temelli yaklaşım ile BT kabiliyetlerinin ölçülmesi yaklaşımı sayesinde daha uzun vadede geçerli olabilecek bir ölçek ortaya koyabilmek mümkün olabilmektedir. Bu sayede diğer örgütsel değişkenler ile ilişkilerin ortaya konabilmesi daha sağlıklı bir biçimde sağlanabilmektedir.

Bu çalışmada Tippins ve Sohi (2003)'nin üç bileşenli BT yetkinliği ölçeğinin Türkçeye uyarlanması amaçlanmıştır. Bu amaçla, birincisi bankacılık sektörü, diğeri ise Ankara ili OSTiM Sanayi Sitesinde; Teknoloji ve Bilişim, Elektrik ve Elektronik ile Makine ve Makine Ekipmanları alt sektörlerinde faaliyet gösteren işletmelerden oluşan iki ayrı örneklem grubundan veri toplanmış ve analizler bu verilere dayalı olarak yapılmıştır.

Ölçeğin Türkçe çevirisinin, Brislin ve arkadaşları (1973) tarafından geliştirilen yöntem ile yapılmasına müteakip, iç tutarlılık ve geçerlilik analizleri yapılmıştır. Ölçeğin iç tutarlılığına yönelik olarak, her bir örneklem grubu için hem alt boyutların hem de tüm ölçeğin Cronbach Alfa katsayıları hesaplanmıştır. Her iki örneklem grubu için, alt boyutlara ait Cronbach Alfa katsayıları birbirine çok yakın değerlerde tespit edilmiştir. Çalışmada iki ayrı örneklem grubu için elde edilen iç tutarlılık değerleri göz önüne alındığında, ölçeğin iç tutarlılığının sağlandığı söylenebilir.

Ölçeğin geçerliliğinin belirlenebilmesi için öncelikle her iki örneklem grubuna da açımlayıcı faktör analizi (AFA) yapılmıştır. Analiz sonucunda, her iki örneklemde de orijinal ölçektekine benzer şekilde maddelerin üç ayrı faktör altında toplandığı görülmüştür. Açıklanan varyans oranları birbirine çok yakın şekilde birinci örneklem için \%79,76 ve ikinci örneklem için \%79,27 olarak belirlenmiştir. Müteakiben her iki örneklem için doğrulayıcı faktör analizi yapılmıştır. Yapılan analizler sonucunda elde edilen uyum değerlerinin kabul edilebilir sınırlar içerisinde veya kabul edilebilir sınırlara çok yakın olduğu belirlenmiş olup ölçeğin üç faktörlü yapısı doğrulanmıştır.

Bahse konu faktörler; BT nesneleri, BT bilgisi ve BT operasyonlarıdır. BT nesneleri; şirketlerin envanterinde bulunan yazılım, donanım ve ağ nesnelerinin sayı ve kalitesini değil, modern sistemlerin sürdürülebilir olması için gereken yapısal özellikler ve anlayışı sorgulayan maddelerden oluşmaktadır. Bu boyutta yüksek puan elde eden şirketlerin BT nesnelerini güncel tutabilme ve bu konuda rekabet edebilme de sürdürülebilir bir yetkinliğe sahip olabileceği beklenmektedir. BT bilgisi boyutu; kurumsal anlamda firmanın BT ile ilgili gerekli güncel bilgi ve yeteneklere sahip olunma 
seviyesini ölçmeyi hedeflemektedir. BT operasyonları boyutu ise şirketlerin olası iş süreçlerinin ne ölçüde BT yetenekleri ile desteklendiğini ortaya koymayı amaçlamaktadır.

Yapılan çok değişkenli istatistiksel analizler sonucunda söz konusu kaynak temelli ölçeğin ülkemiz için de geçerli olduğu görülmüştür. Bu çalışma ile tespit edilen bu durum konu ile ilişkili araştırmalar yapacak akademisyenler için Türkiye örnekleminde kullanabilecekleri bir ölçek yazına kazandırılmıştır. Son haliyle Ek'te sunulan ölçek formunun ilgili alanlarda yapılacak gelecekteki araştırmalara katkı sağlayabileceği düşünülmektedir.
Bir ölçeğin başka bir kültürde kullanılabilirliğini denemek maksadıyla yapılması gereken açımlayıcı ve doğrulayıcı faktör analizleri ve Cronbach'ın Alfa İç Tutarlılık testi vasıtasıyla iki farklı örneklem üzerinden elde edilen veriye dayalı olarak belirlenen geçerlik ve güvenilirlik durumu sadece araştırmanın yürütüldüğü katılımcılar çerçevesinde sınırlılığa sahiptir. Ülkedeki tüm işletmelerde geçerli ve güvenilir olduğu şeklinde bir genelleme yapabilmek için farklı bölgelerde, farklı sektörlerde ve farklı ölçekte şirketler üzerinde aynı ölçeğinin denenmesi gerektiği bilinmelidir. 


\section{KAYNAKLAR}

Anderson J.C. ve Gerbing D.W. (1984) “The Effect of Sampling Error on Convergence, Improper Solutions, and Goodness-of-Fit Indices For Maximum Likelihood Confirmatory Factor Analysis” Psychometrika, 49:155-173.

Barney J.B. (1991) "Firm Resources and Sustained Competitive Advantage" Journal of Management, 17(1):99-120.

Barney, J.B., Wright, M. ve Ketchen, DJ.Jr. (2001) "The Resource-Based View of the Firm: Ten Years After 1991" Journal of Management, 27:625-641.

Bartel, A., Ichniowski, C. ve Shaw, K. (2007) "How Does İnformation Technology Affect Productivity? PlantLevel Comparisons of Product Innovation, Process Improvement, and Worker Skills" The Quarterly Journal of Economics, 122(4):1721-1758.

Becker, A., Hagenberg, N., Roessner, V., Woerner, W. ve Rothenberger, A. (2004) "Evaluation of the SelfReported Sdq in A Clinical Setting: Do Self-Report Tell Us More Than Ratings By Adult Informants? European Child ve Adolescent Psychiatry, 13:17-24.

Bensaou, M. (1993) "Interorganizational Cooperation: The Role of Information Technology An Empirical Comparison of US and Japanese Supplier Relations" 14th Annual International Conference on Information Systems (ICIS), December 5-8, Orlando, FL, USA.

Bensghir, K.T. (1996) Bilgi Teknolojileri ve Örgütsel Değişim, 1.Baskı, Ankara, TODAİE Yayınları.

Bharadwaj, A.S. (2000) "A Resource-Based Perspective on Information Technology Capability and Firm Performance: An Empirical Investigation”, MIS Quarterly, 24(1):169-196.

Bollen, K.A. (1989) Structural Equations With Latent Variables, 1st Edition, NewYork, Wiley.

Brislin, R.W., Lonner, W.J. ve Thorndike, R.M. (1973) Cross-Cultural Research Methods, 1st Edition, Canada, John Wiley\&Sons Pub.

Browne, M.W. ve Cudeck, R. (1993) "Alternative Ways of Assessing Model Fit" K.A. Bollen ve J.S. Long (eds.), Testing Structural Equation Models,nNewbury Park, CA, USA, Sage Publications.

Bülbül, H. ve Demirer, Ö. (2008) "Hizmet Kalitesi Ölçüm Modelleri SERVQUAL ve SERPERF'in Karşılaştırmalı Analizi” Selçuk Üniversitesi Sosyal Bilimler Enstitüsü Dergisi, 20:181-198.

Büyüköztürk, Ş. (2007) Sosyal Bilimler İçin Veri Analizi El Kitabı, 7. Baskı, Ankara, Pegem A Yayıncılık.

Byrne, B.M. (1994) Structural Equation Modeling With EQS and EQS/Windows, Thousand Oaks, CA, USA, Sage Publications.
Chan, S.L. (2000) "Information Technology in Business Processes" Business Process Management Journal, 6(3):224-237.

Clemons E.K. ve Row M.C. (1991) "Sustaining IT Advantage: The Role of Structural Differences" MIS Quarterly, 15(3):275-294.

Eser, U. (1991) “Türkiye İmalat Sanayii’nde Verimlilik, Teknolojik Gelişme ve Büyümenin Kaynakları” 1. Verimlilik Kongresi Bildirilen Kitabı, Ankara, MPM Yayın No: 454

Evangelista, R. ve Vezzani, A. (2011) “The Impact of Technological and Organizational Innovations on Employment in European Firms", Industrial and Corporate Change, First Published Online: November 10, 2011, (http://icc.oxfordjournals.org/ content/early/2011/11/10/icc.dtr069.abstract, (17.01.2012).

Fernández-Mesa, A., Ferreras-Méndez, J., Alegre-Vidal, J. ve Chiva-Gómez, R. (2012) “IT Competency, Internal and External Learning Competency and the Commercial Success of Innovation" Proceedings of the European Conference on Knowledge Management, 1: 321-330.

Gibb J. ve Haar J. (2007) "IT Competency Predicting Market and Development Performance: Moderated By Organizational Size” Polytechnic University of Valencia, Proceedings of European and Mediterranean Conference on Information Systems(EMCIS2007), 24-26 Haziran 2007, Valencia.

Giuri, P., Torrisi, S. ve Zinovyeva, N. (2008) "ICT, Skills, and Organizational Change: Evidence From Italian Manufacturing Firms" Industrial and Corporate Change, 17(1):29-64.

Gurbaxani, V. ve Whang, S. (1991) "The Impact of Information Systems on Organizations and Markets" Communications of the ACM, 34(1):59-73.

Güleş, H.K., Gözlü, K. ve Tekin, S. (2003) "Information Technology Implementation in Newly Industrialising Countries: The Case of Turkish Manufacturing Firms” Endüstri Mühendisliği,14(3):30-37.

Hsu, I.C. ve Sabherwal, R. (2011) "From Intellectual Capital to Firm Performance: The Mediating Role of Knowledge, Management Capabilities" IEEE Transactions on Engineering Management, 58(4):626-642.

Hu, L.T., ve Bentler, P.M. (1995) "Evaluating Model Fit”, R.H. Hoyle (eds.), Structural Equation Modeling: Concepts, Issues, and Applications, Thousand Oaks, CA, USA, Sage Publication.

Huber, G.P. (1990) "A Theory of the Effects of Advanced Information Technologies on Organizational Design, Intelligence, and Decision Making" The Academy of Management Review, 15(1):47-71. 
Itami, H. (1987) Mobilizing Invisible Assets, 1st Edition, Cambridge, MA, Harvard University Press.

Kmieciak, R., Michna, A. ve Meczynska, A. (2012) "Innovativeness, Empowerment and IT Capability: Evidence From SMEs. Industrial Management ve Data Systems, 112(5):707-728.

Lei, D., Hitt, M.A., Bettis R. (1996) "Dynamic Core Competencies Through Meta-Learning and Strategic Context" Journal of Management, 22(4):549-569.

Li, E.Y., Chen, J. S. ve Huang, Y.H. (2006) "A Framework For Investigating the Impact of IT Capability and Organisational Capability on Firm Performance in the Late Industrialising Context" International Journal of Technology Management, 36(1-2-3):209-229.

Loukis, E., Soto-Acosta, P. ve Pazalos, K. (2009) "Analyzing the Mediating Role of ICT and Non-ICT Investment and BPR in the Relationship Between E-Business Adoption and Perform" Dokuz Eylül Üniversitesi, European and Mediterranean Conference on Information Systems (EMCIS2009), 13-14 Temmuz 2009, İzmir.

Madureira, A, Baken, N. ve Bouwman, H. (2011) "Value of Digital Information Networks: A Holonic Framework" Netnomics, 12(1):1-30.

Majumdar, S.K., Carare, O. ve Chang, H. (2010) "Broadband Adoption and Firm Productivity: Evaluating the Benefits of General Purpose Technology", Industrial and Corporate Change, 19(3):641-674.

Malone, T.W., Yates, J. ve Benjamin, R.I.(1987) "Electronic Markets and Electronic Hierarchies" Communications of the ACM, 30:484-497.

Marsh, H.W. ve Hocevar, D. (1985) "Application of Confirmatory Factor Analysis To the Study of Self-Concept: First- and Higher-Order Factor Models and Their Invariance Across Groups" Psychological Bulletin, 97:562-582.

Martinsons, M.G. ve Martinsons, V. (2002) "Rethinking the Value of IT, Again" Communications of the ACM, 45(7):25-26.

Melville, N., Kraemer, K. ve Gurbaxani, V. (2004) "Review: Information Technology and Organizational Performance: An Integrative Model of IT Business Value, MIS Quarterly, 28 (2): 283-322.

Meyers, L.S., Gamst, G.C. ve Guarino, C. (2005) Applied Multivariate Research: Design and Interpretation, SAGE Publications.

Michael, J. ve Handel, M.J. (2003) "Implications of Information Technology For Employment, Skills, and Wages: A Review of Recent Research" Final Report SRI International, SRI Project Number P10168, http://www. sri.com/policy/_csted/reports/sandtit/Handel_IT_Employment_Main_Rept.pdf, (17.01.2012).
Michie, J. ve Sheehan, M. (1999) "HRM Practices, R\&D Expenditure and Innovative Investment: Evidence From the UK's 1990 Workplace Industrial Relations Survey (WIRS)" Industrial and Corporate Change, 8(2):211234.

Moshiri, S. ve Simpson, W. (2011) "Information Technology and the Changing Workplace in Canada: Firm-Level Evidence" Industrial and Corporate Change, 20(6):1601-1636.

Ong, J.W. ve Bin Ismail, H. (2008) "Sustainable Competitive Advantage through Information Technology Competence: Resource-Based View on Small and Medium Enterprises" Communications of the IBIMA, 1:62-70.

Porter, M.E. ve Millar, V.E. (1985) "How Information Gives You Competitive Advantage" Harvard Business Review, 63(4):149-160.

Powell, T.C ve Dent-Micallef, A. (1997) "Information Technology As Competitive Advantage: The Role of Human, Business, and Technology Resources" StrategicManagement Journal, 18(5):375-405.

Said, J., Hui, W.S., Taylor, D. ve Othman, R. (2009) "Customer-Focused Strategies and Information Technology Capabilities: Implications For Service Quality of Malaysian Local Authorities" International Review of Business Research Papers, 5(3):241-256.

Santhanam, R. ve Hartono, E. (2003) "Issues in Linking Information Technology Capability To Firm Performance" MIS Quarterly, 27(1):125-153.

Savaşır, I. (1994) "Ölçek Uyarlamasındaki Bazı Sorunlar ve Çözüm Yolları”, Türk Psikoloji Dergisi, 33(9):27-32.

Schendel, D. (1996) "Knowledge and the Firm" Strategic Management Journal, 17: 1-4.

Schermelleh, E.K., Moosbrugger, H. ve Müler, H. (2003) "Evaluating the Fit of Structural Equation Models: Tests of Significance and Descriptive Goodness-of-Fit Measures", Methods of Psychological Research Online, 8(2): 23-74.

Schumacker, R.E., ve Lomax, R.G. (2004) A Beginner's Guide to Structural Equation Modeling, 2nd Edition. Mahwah, NJ, USA, Lawrence Erlbaum Associates.

Sharp, J.M., Irani, Z. ve Desai, S. (1999) "Working Towards Agile Manufacturing in the UK Industry" International Journal of Production Economics, 62 (1-2):155-169.

Sircar, S., Turnbow, J.L. ve Bordoloi, B. (2000) "A Framework For Assessing the Relationship Between Information Technology Investments and Firm Performance" Journal of Management Information Systems, 16(4):69-97.

Steiger, J.H. (1990) "Structural Model Evaluation and Modification: An Interval Estimation Approach" Multivariate Behavioural Research, 25:173-180. 
Stewart A.T. (2000) Entelektüel Sermaye, 1. Baskı, İstanbul, Konent Kitap.

Tabachnick, B.G. ve Fidell, L.S. (2007) Using Multivariate Statistics, 5th Edition, Boston, USA, Pearson.

Tanriverdi, H. (2005) "Information Technology Relatedness, Knowledge Management Capability, and Performance of Multibusiness Firms MIS Quarterly, Special Issue on Information Technologies and Knowledge Management, 29 (2): 311-334.

Tavşancıl, E.(2002) Tutumların Ölçülmesi ve SPSS ile Veri Analizi, 1.Baskı, Ankara, Nobel Yayınları.

Thatcher, M.E. ve Oliver, J.R. (2001) “The Impact of Technology Investments on A Firm's Production Efficiency, Product Quality, and Productivity" Journal of Management Information Systems, 18(2):17-45.

Tippins, M.J. ve Sohi, R.S. (2003) "IT Competency and Firm Performance: Is Organizational Learning A Missing Link?” Strategic Management Journal, 24:745761.
Turan, A.H. (2009) "Küçük ve Orta Büyüklükteki İşletmelerde (KOBİ) Bilişim Teknolojileri (BT), Örgütsel Rekabetçi Stratejileri ve Başarım İlişkisi”, Atatürk Üniversitesi İktisadi ve İdari Bilimler Dergisi, 23(3):105-122.

Ullman, J.B. (2001) "Structural Equation Modeling" B.G. Tabachnick et al (eds.) Using Multivariate Statistics, 4th Edition, Needham Heights, MA, USA, Allyn \&Bacon Inc.

Zerenler, M. (2007) "Information Technology and Business Performance in Agile Manufacturing: An Empirical Study in Textile Industry", Proceedings of Fourth International Conference on Information Technology(ITNG '07), 2-4 Nisan 2007, Las Vegas.

Zhou, Y. ve Chen, X. (2009) "Recap the Mediating Function of ICT in Service Process: A Framwork of Life Cycle Analysis" Proceedings of International Conference on Management and Service Science (MASS 2009), September 20-22, Wuhan/Beijing, China. 


\section{EKLER}

Ek-A: Bilgi Teknolojileri Yetkinliği Anketi

\begin{tabular}{|c|c|c|c|c|c|c|c|c|}
\hline 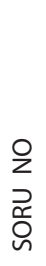 & $\begin{array}{l}\text { Aşağıda firmanızın BT Yeteneklerini belirlemeye yönelik ifadeler yer almaktadır. Lütfen bu } \\
\text { ifadelere ne derecede katılığınızı oluşturulan bir ölçek üzerinden sadece bir seçeneği } \\
\text { seçerek işaretleyiniz. }\end{array}$ & 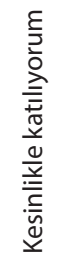 &  & 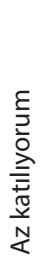 &  &  & 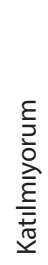 & 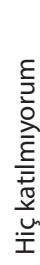 \\
\hline 1 & $\begin{array}{l}\text { Firmamız bilgisayar tabanlı sistemler ile pazar ve müşteriler ile ilgili bilgilerini toplama ve } \\
\text { analiz etme kabiliyetine sahiptir }\end{array}$ & 7 & 6 & 5 & 4 & 3 & 2 & 1 \\
\hline 2 & $\begin{array}{l}\text { Harici veri tabanlarındaki pazar bilgilerine erişmek için düzenli olarak bilgisayar tabanlı } \\
\text { sistemlerimizi kullanırız. }\end{array}$ & 7 & 6 & 5 & 4 & 3 & 2 & 1 \\
\hline 3 & Müşteri bilgilerini çevrimiçi kaynaklardan toplayan bir takım imkânlarımız mevcuttur. & 7 & 6 & 5 & 4 & 3 & 2 & 1 \\
\hline 4 & Müşteri ve Pazar bilgilerini analiz etmek için bilgisayar tabanlı sistemler kullanırız. & 7 & 6 & 5 & 4 & 3 & 2 & 1 \\
\hline 5 & Müşteri bilgilerini yönetmede sık sık karar destek sistemlerimizi devreye sokarız. & 7 & 6 & 5 & 4 & 3 & 2 & 1 \\
\hline 6 & $\begin{array}{l}\text { Müşterilerimiz hakkındaki bilgilere erişmede, onları depolamada ve işlemede bilgisayar } \\
\text { tabanlı sistemlere güveniriz. }\end{array}$ & 7 & 6 & 5 & 4 & 3 & 2 & 1 \\
\hline 7 & Şirketimizde resmi bir BT departmanı mevcuttur & 7 & 6 & 5 & 4 & 3 & 2 & 1 \\
\hline 8 & $\begin{array}{l}\text { Şirketimiz temel görevleri arasında bilgi teknolojilerimizi yönetmek olan bir yönetici } \\
\text { istihdam etmektedir. }\end{array}$ & 7 & 6 & 5 & 4 & 3 & 2 & 1 \\
\hline 9 & $\begin{array}{l}\text { Firmamız her yıl yeni BT donanım ve yazılımlarının tedariki için önemli miktarda para } \\
\text { ayırmaktadır. }\end{array}$ & 7 & 6 & 5 & 4 & 3 & 2 & 1 \\
\hline 10 & İhtiyaç olduğunda firmamız özel tasarım yazılım uygulamaları geliştirebilir. & 7 & 6 & 5 & 4 & 3 & 2 & 1 \\
\hline 11 & Firmamız çalışanları bilgisayar ağı ile birbirlerine bağlanmıştır & 7 & 6 & 5 & 4 & 3 & 2 & 1 \\
\hline 12 & $\begin{array}{l}\text { Genel itibariyle teknik destek personelimiz bilgisayar tabanlı sistemler konusunda bilgi } \\
\text { sahibidir }\end{array}$ & 7 & 6 & 5 & 4 & 3 & 2 & 1 \\
\hline 13 & Firmamız yüksek seviyede bilgisayar tabanlı uzmanlığa sahiptir. & 7 & 6 & 5 & 4 & 3 & 2 & 1 \\
\hline 14 & Bilgisayarlara ilgili yenilik ve buluşları konusunda bilgi sahibiyiz. & 7 & 6 & 5 & 4 & 3 & 2 & 1 \\
\hline 15 & Müşterilerimiz ile bilgisayar tabanlı iletişim tesis ve idame edebilecek bilgilere sahibiz. & 7 & 6 & 5 & 4 & 3 & 2 & 1 \\
\hline
\end{tabular}


